\title{
ANESTESIA GENERAL PARA CESÁREA EN PACIENTE CON PARAPARESIA ESPÁSTICA ASOCIADA AL VIRUS LINFOTRÓPICO DE LAS CÉLULAS T HUMANAS TIPO 1
}

\author{
Marjorie Lisseth Calderón Lozano1,a , Deisy Mirella Tejada Chacón ${ }^{1, b}$, María Victoria Quispe Gómez,b, \\ Victor Wilfredo Ontón Reynaga ${ }^{2, c}$.
}

\begin{abstract}
RESUMEN
La paraparesia espástica es una infección causada por el virus linfotrópico de células T humanas (HTLV-1). Se caracteriza por una mielopatía de lenta instauración que compromete principalmente los miembros inferiores. Afecta más a mujeres que a varones y las principales vías de transmisión son: sanguínea, sexual y vertical (principalmente durante la lactancia).

Se presenta el caso de una gestante de 28 años de edad, y 38 semanas de gestación, con diagnóstico de paraparesia espástica asociada a HTLV-1; programada para cesárea; en quién se empleó una técnica anestésica general balanceada.

En conclusión, la anestesia general balanceada fue una opción segura para el manejo anestésico de la cesárea en esta paciente, brindando una adecuada relajación muscular durante la cirugía, con mínimos cambios hemodinámicos, además de una rápida recuperación del bloqueo neuromuscular.
\end{abstract}

Palabras claves: Paraparesia espástica, HTLV-1, cesárea, anestesia general, manejo anestésico. (Fuente: DeCS BIREME)

\section{GENERAL ANESTHESIA FOR CAESAREAN SECTION IN A PATIENT WITH SPASTIC PARAPARESIA ASSOCIATED WITH TYPE 1 HUMAN T-CELL LYMPHOTROPIC VIRUS.}

\begin{abstract}
Spastic paraparesis is an infection caused by the human T-cell lymphotropic virus (HTLV-1). It is characterized by a slowonset myelopathy that mainly affects the lower limbs. It affects more women than men and the main routes of transmission are: blood, sexual and vertical (mainly during lactation).

We present the case of a 28-year-old pregnant woman, 38 weeks of gestation, diagnosed with spastic paraparesis associated with HTLV-1; scheduled for cesarean section; in whom a balanced general anesthetic technique was used.

In conclusion, balanced general anesthesia was a safe option for the anesthetic management of cesarean section in this patient, providing adequate muscle relaxation during surgery, with minimal hemodynamic changes, in addition to a rapid recovery from neuromuscular block.
\end{abstract}

Key words: Spastic paraparesis, HTLV-1, caesarean section, general anesthesia, anesthetic management. (Source: MeSH NLM).

\section{INTRODUCCIÓN}

El virus linfotrópico de células $\mathrm{T}$ humanas pertenece a la familia Retroviridae, su presencia en el mundo entero, incluye una prevalencia mayor en zonas como Japón, África subsahariana, El Caribe, Centroamérica y Sudamérica. ${ }^{1}$ En el Perú solo hay tres estudios de la seroprevalencia en gestantes encontrándose en Lima y Quillabamba prevalencias superiores al $1 \% .^{2}$ No hay reportes de otros datos epidemiológicos de seroprevalencia de HTLV-1 en gestantes debido a que los exámenes para su detección no están incluidos en el paquete de atención prenatal. ${ }^{3}$

Las principales vías de transmisión de la infección por HTLV son: la vía sanguínea, sexual y vertical. ${ }^{1}$ Sin embargo, a diferencia del VIH, la transmisión madre a hijo ocurre principalmente a través de la lactancia materna (una duración mayor a 6 meses, está asociada a mayor riesgo), la transmisión durante el parto es infrecuente, no constituyendo indicación de cesárea cuando el cuadro

\footnotetext{
Instituto Nacional Materno Perinatal. Lima-Perú.

a Médico Anestesióloga.

b Médico Residente.

Hospital Materno Infantil Rímac. Lima-Perú.

Médico Anestesiólogo

Citar como: Calderón ML, Tejada DM, Quispe MV, Onton VW. Anestesia general para cesárea en paciente con paraparesia espástica asociada al virus linfotrópico de las células T humanas tipo 1. Rev Peru Investig Matern Perinat 2020; 9(4):29-32 DOI https://doi.org/10.33421/inmp.2020207
}

Recibido: 13-11-20 Aprobado: 30-12-20 
clínico no lo amerita. ${ }^{5}$ Hasta el $90 \%$ de los pacientes infectados son portadores asintomáticos. , $^{4,5}$

La paraparesia espástica asociada a HTLV-1, es considerada la manifestación neurológica más común de ésta, afectando en mayor proporción a mujeres y personas mayores de 40 años de diferentes razas y condiciones sociales. Este trastorno neurológico de la motoneurona superior afecta predominantemente al cerebro y la médula espinal, comportándose como una mielopatía de instauración lenta y progresiva. ${ }^{4}$

Las pacientes con paraparesia espástica pueden preceder con un cuadro clínico, caracterizado por disfunción sexual y alteraciones de esfínteres. Otros síntomas inespecíficos son las disestesias y parestesias en miembros inferiores. Posteriormente se puede agregar lumbalgia, ataxia cerebelosa, disminución de la fuerza muscular de miembros inferiores con espasticidad, hipertonía asimétrica que progresa con el tiempo a la simetría, mioclonías, marcha espástica o en tijera, pudiendo progresar a la incapacidad de la paciente. ${ }^{4}$

Existe escasa literatura sobre el manejo anestésico en gestantes con paraparesia espástica asociada a HTLV-1. Perú, es uno de los países con mayores tasas de prevalencia a nivel sudamericano, por lo que el conocimiento del manejo anestésico y la implicancia de esta patología en la gestante, permitirá orientarnos para proveer una anestesia segura.

\section{PRESENTACIÓN DEL CASO}

Tercigesta nulípara de 28 años de edad, y 38 semanas de edad gestacional, con diagnóstico de paraparesia espástica asociada a HTLV-1; programada para cesárea categoría 4; mestiza, habitante permanente de Lima, cuyos síntomas comenzaron 16 años atrás, con debilidad de miembros inferiores que posteriormente dificultó la deambulación, siendo diagnosticada hace 2 años de paraparesia espástica asociada a HTLV-1, por lo que recibió tratamiento con lamivudina, pero abandonó la terapia a los pocos meses. Entre otros antecedentes, se le realizó dos legrados uterinos por abortos espontáneos, sin estudios adicionales.

Al examen neurológico: consciente y orientada en las tres esferas. No presenta compromiso de funciones cognitivas. Fuerza motora $5 / 5$ en miembros superiores y $3 / 5$ en miembros inferiores. Hipertonía e hiperreflexia en miembros inferiores, reflejo de Babinsky positivo bilateral, Hoffman negativo, marcha en tijeras. Sin alteraciones en la sensibilidad superficial, profunda, vibración ni propiocepción.

Al examen neumológico y cardiovascular no presenta alteraciones. Riesgo cardiológico grado 1 (Score de Goldman). Al examen: la clasificación del estado físico de acuerdo a la Sociedad Americana de Anestesiología (ASA) III, peso $65 \mathrm{~kg}$, talla $145 \mathrm{~cm}$, IMC: 30.92, presión arterial: 108/70 mmHg; frecuencia cardiaca: 77/min. Apertura oral igual a $3 \mathrm{~cm}$, distancia tiromentoniana mayor a $6 \mathrm{~cm}$, Mallampati modificado grado 2, movilidad cervical conservada. Exámenes de laboratorio: Hemoglobina: 9.6 g/dl., Tiempo de Protrombina: 12 segundos, Tiempo parcial de Tromboplastina: 33 segundos, Fibrinógeno: $527 \mathrm{mg} /$ dl., Recuento de plaquetas: $244000 / \mathrm{mm}^{3}$. Se explica a la paciente las técnicas anestésicas y luego de mencionarle los riesgos y beneficios de éstas, se considera la técnica general balanceada, previo consentimiento firmado.

El día de la cirugía, previo a la inducción anestésica, se administró $50 \mathrm{mg}$ de ranitidina, $10 \mathrm{mg}$ de metoclopramida y $200 \mathrm{mg}$ de hidrocortisona vía intravenosa. Se realizó monitorización ASA básica, BIS (Índice Biespectral), TOF (tren de cuatro) y preparación de equipo de vía aérea difícil y sonda de aspiración. Se preoxigenó e inició la inducción de secuencia rápida con $3 \mathrm{ug} / \mathrm{Kg}$ de fentanilo, $2 \mathrm{mg} / \mathrm{Kg}$ de propofol, y $1 \mathrm{mg} / \mathrm{Kg}$ de rocuronio, lográndose la intubación al primer intento, sin importantes variaciones en los parámetros hemodinámicos, el mantenimiento anestésico se realizó con sevofluorane para alcanzar un BIS entre 40-60.

El nacimiento del producto se produjo a los 3 min de iniciada la cirugía dando como resultado un recién nacido femenino, con un peso de $3380 \mathrm{~g}$, talla de $50 \mathrm{~cm}$, Apgar 7 y 9 al minuto y a los 5 minutos, respectivamente. Se administró $3 \mathrm{UI}$ de oxitocina vía intravenosa, y se continuó con infusión de $3 \mathrm{UI}$ por hora. Adicionalmente se agregó ergometrina $0,2 \mathrm{mg}$ vía intramuscular. No se requirió del uso de vasopresores. Se manejó la analgesia postoperatoria con $2 \mathrm{~g}$ de metamizol y 150 mg de tramadol vía intravenosa. La cirugía transcurrió sin incidencias durante un total de 30 minutos. El sangrado intraoperatorio fue de $500 \mathrm{ml}$ y se obtuvo una diuresis de $50 \mathrm{ml}$; procediendo a la extubación de la paciente, previa reversión con sugammadex $2 \mathrm{mg} / \mathrm{Kg}$ con recuperación total del bloqueo neuromuscular (TOF $>0.9$ ).

Pasó al Servicio de Recuperación Postanestésica, donde permaneció las siguientes 2 horas. Los exámenes de laboratorio al alta fueron: Hemoglobina: $10.8 \mathrm{~g} / \mathrm{dl}$, Tiempo de Protrombina: 13 segundos, Tiempo parcial de Tromboplastina: 31 segundos, Fibrinógeno: $580 \mathrm{mg} / \mathrm{dl}$, Recuento de plaquetas: $240000 / \mathrm{mm}^{3}$. No se reportaron complicaciones postoperatorias.

\section{DISCUSIÓN}

La gestante con paraparesia espástica por HTLV-1, es considerada un reto para el anestesiólogo, siendo diversas las consideraciones anestésicas a tener en cuenta. En la evaluación preanestésica, debe considerarse la medicación recibida como parte de la terapia inmunomoduladora (corticoides o terapia antiviral), las pacientes que reciben glucocorticoides deben mantener esta medicación a lo largo del perioperatorio, dosis inferiores a las que 
usualmente vienen recibiendo se han asociado a hipotensión refractaria y alteraciones en los volúmenes de eyección cardiaca, considerando dosis de 200 mg en casos de cirugía mayor, como la cesárea. ${ }^{6,7}$

Aunque existen escasos reportes del empleo de la anestesia neuroaxial, como técnica espinal, epidural o espinal-epidural (CSE), en los cuales no se ha evidenciado complicaciones neurológicas postoperatorias; $8,9,10$ aún existe el temor que posibles manifestaciones neurológicas sean atribuidas al abordaje del neuroeje. ${ }^{6}$ Tradicionalmente el compromiso neurológico se ha considerado una contraindicación relativa en la anestesia neuroaxial, por lo que optamos en nuestra paciente por una anestesia general balanceada.

Entre los hipnóticos empleados en la inducción, se prefirió el uso de propofol a dosis recomendadas para inducción de secuencia rápida en gestantes $(2-2.8 \mathrm{mg} / \mathrm{Kg}) .{ }^{11}$ Nitahara, reportó que el propofol a dosis de $(2-3 \mathrm{mg} / \mathrm{Kg})$ produjo una disminución de la actividad electromiográfica sin alteración de la velocidad de conducción en pacientes con paraparesia espástica. ${ }^{12}$ En relación al uso de relajantes musculares, debemos recordar que en pacientes denervados existen abundantes receptores musculares colinérgicos por fuera de la unión neuromuscular, lo que aumenta su sensibilidad a acetilcolina y por ende el riesgo de hiperpotasemia (aumento del potasio sérico en $3 \mathrm{mmol} / \mathrm{L}$ ) con la subsecuente posibilidad de parada cardiaca. ${ }^{6,13}$ Debido a lo anteriormente mencionado y considerando que en la gestante se debe realizar una inducción de secuencia rápida, ${ }^{11}$ preferimos emplear rocuronio $(1 \mathrm{mg} / \mathrm{kg})$, pues provee condiciones similares a la succinilcolina para intubación en gestantes, siendo una excelente alternativa cuando está última está contraindicada. Además, el uso de dosis de cebado con relajantes musculares no despolarizantes para acortar el tiempo de intubación no es recomendado en gestantes pues podría resultar en parálisis completa e incrementar el riesgo de aspiración. ${ }^{11}$

Si bien, se considera que los relajantes musculares no despolarizantes pueden inducir un efecto prolongado, ${ }^{6}$ Sugimoto y Kanmura reportaron casos donde el empleo de vecuronio no se asoció a un mayor tiempo de bloqueo neuromuscular. ${ }^{9,13}$ En nuestro caso, si bien no tuvimos prolongación en el tiempo de bloqueo, el tiempo operatorio corto de la cesárea, asociado a un bloqueo moderado registrado en el TOF, nos orientó a realizar la reversión de éste con sugammadex a dosis de $2 \mathrm{mg} /$ $\mathrm{kg}$, se prefirió este fármaco debido a su efectividad comprobada en gestantes sometidas a cesárea, con rápida recuperación sin recurarización en bloqueo neuromuscular por rocuronio. ${ }^{8}$

Entre las principales fortalezas de este caso tenemos, el trabajo en equipo, la disponibilidad de equipamiento, monitores e insumos para un manejo anestésico seguro. Las principales limitaciones de este reporte son la descripción del manejo anestésico de un solo caso, y la escasa bibliografía de las consideraciones anestésicas de esta patología en la gestante.

En conclusión, la anestesia general balanceada fue una opción segura para el manejo anestésico de la cesárea en esta paciente con paraparesia espástica asociada a HTLV1 , brindando una adecuada relajación muscular durante la cirugía, con mínimos cambios hemodinámicos, además de una rápida recuperación del bloqueo neuromuscular. Por otro lado, se sugiere realizar un estudio detallado de la historia clínica que permita continuar u optimizar el tratamiento habitual de la paciente, guiar el manejo anestésico basándose en la fisiología de la gestante, considerando a su vez la interacción de los medicamentos empleados en el perioperatorio, como es el caso de los relajantes musculares despolarizantes que son evitados en este tipo de pacientes.

\section{Responsabilidades éticas}

\section{Protección de personas y animales.}

Los autores declaran que para esta investigación no se han realizado experimentos en seres humanos ni en animales.

\section{Confidencialidad de los datos.}

Los autores declaran que han seguido los protocolos de su centro de trabajo sobre la publicación de datos de pacientes.

Derecho a la privacidad y consentimiento informado. Los autores han obtenido el consentimiento informado de los pacientes y/o sujetos referidos en el artículo. Este documento obra en poder del autor de correspondencia.

\section{REFERENCIAS BIBLIOGRÁFICAS}

1. Ponce AM, Del Corral I, Ortiz M, Anciones C, Mateos ML. Paraparesia espástica tropical autóctona en la Comunidad de Madrid. Experiencia en el cribado del virus linfotrópico de células T humanas tipo I. Enferm Infecc Microbiol Clin. 2015.

2. Alarcón J, Romaní F, Montano S, Zunt JR. Transmisión vertical de HTLV-1 en el Perú. Rev Peru Med Exp Salud Pública. 2011; 28(1):101-108.

3. Monteiro DL, Taquette SR, Sodre' Barmpas DB, Rodrigues NC, Teixeira SA, Villela LH et al. Prevalence of HTLV-1/2 in Pregnant Women Living in the Metropolitan Area of Rio de Janeiro. PLoS Negl Trop Dis. 2014;9(8): e3146.

4. Rivera-Caldón CC, López-Valencia D, Zamora-Bastidas TO, Dueñas-Cuéllar RA, Mora-Obando DL. Infección por el virus linfotrópico humano de células T tipo 1 (HTLV-1) y paraparesia espástica. Avances y diagnóstico 35 años después de su descubrimiento. latreia. 2017 Abr-Jun;30(2):146-159.

5. Gotuzzo E, González E, Verdonck K, Mayer E, Ita F, Clark D. Veinte años de investigación sobre HTLV-1 y sus complicaciones médicas en el Perú: Perspectivas generales. Acta Med Per 27(3) 2010. 
6. Poveda-Jaramillo R, Pacheco A, Martínez A. Tropical spastic paraparesis and anesthesia, case report and topic review. Rev ColombAnestesiol. 2012; 40:162---6.

7. Rodrigues M, Cabral F, Pina F. Tropical spastic paraparesis --anesthetic approach. Rev Bras Anestesiol. 2017;67(6):651--654.

8. Yuasa H, Higashizawa T, Koga Y. Spinal anesthesia in human T lymphotropic virus type I-associated myelopathy. Anesth Analg. 2001 Jun;92(6):1618.

9. Sugimoto K, Ohmori A, Iranami H, Hatano Y. Tramadol, Vecuronium, and Thoracic Epidural Ropivacaine Combined with Sevoflurane Anesthesia in a Patient with Human T-Lymphotropic Virus Type 1-Associated Myelopathy. Anesth Analg. 2006 Dec; 103(6):1596.

10. Yokomizo T, Hiraki T, Mishima Y, Ushijima K. [Combined spinal-epidural anesthesia for a patient with HTLV-1 associated myelopathy]. Masui. 2014 Aug;63(8):918-20.

11. Lawrence C. Tsen, MD. Anesthesia for Cesarean Delivery. In: Chestnut DH (Ed). Obstetric Anesthesia, 5th edition. Philadelphia;2014. p.571
12. Nitahara K, Matsuyama M, Sakuragi T, Higa K. Depression of evoked electromyographic (EEMG) responses by propofol in a patient with human T-cell lymphotropic virus type l-associated myelopathy (HAM). Anesth Analg. 2000;91: 755.

13. Kanmura Y, Komoto R, Kawasaki K, Yoshimura N. Anesthetic considerations in myelopathy associated with human T-cell lymphotropic virus type I (HTLV-I-associated myelopathy: HAM). Anesth Analg.1996; 83(5):1120-1.

\section{Correspondencia:}

Marjorie Lisseth Calderón Lozano.

Dirección: Calle Raymundo Carcamo 639 Dpto 102. Urb Santa Catalina - La Victoria

de Porres

Correo: marjorie_163@hotmail.com

Teléfono: 51918839858 